\title{
Reseña: Mediación familiar y alienación parental (2020) de María José Briz Clariget
}

Caterine Valdebenito Larenas

ORCID: 0000-0002-3684-0066

Universidad Andrés Bello, Chile

Correo: caterine.valdebenito@unab.cl

El libro escrito por María José Briz Clariget da cuenta del quehacer reflexivo realizado en su tesis doctoral, donde aborda la complejidad de las temáticas de la mediación familiar y el llamado síndrome de alienación parental, que revisa a la luz de su experiencia profesional en la realidad uruguaya, donde explica que el sistema judicial litigioso actual no brinda respuestas adecuadas para los complejos conflictos familiares que tienen lugar en la sociedad actual, tras el divorcio y/o separación de los padres.

La autora, toma el conflicto como punto de partida del análisis para el abordaje de la mediación desde la perspectiva de una instancia socio jurídica que permitiría la realización de un proceso de resolución de conflictos, destacando los principios básicos de esta, el rol del mediador dentro del proceso: los aspectos tangibles, la autopercepción del propio rol y las expectativas de las partes sobre la figura del/a mediador/a, favoreciendo la multiparcialidad en la complejidad de los procesos de ayuda. Continúa con una breve descripción de los llamados modelos clásicos de la mediación transformativo, de Bush y Folger; circular narrativo, de Cobb y Harvard con Ury-, y suma el modelo relacional de Clemente García y Carles, que permite relevar el componente relacional en los conflictos interpersonales.

El primer capítulo inicia mirando el acceso a la justicia, introduce la mediación familiar dentro del sistema de justicia, y explica la estructura y funcionamiento de la atención de las causas, donde los componentes relacional e interaccional tienen un rol clave en la existencia de conflicto. Hace una clara mención de los conflictos familiares existentes al alero de los procesos de divorcio, marcados por una mirada confrontacional y la importancia de incorporar en la mediación la responsabilización de sus acciones y dichos a la díada conyugal, para lo cual el profesional de mediación tiene que cubrir aspectos claves, en los que recoge a Kessler para relevar los recursos de las personas y la mirada de futuro. 
Cabe destacar en este punto la especial atención que otorga a los principios éticos de la mediación, que ordena en torno a los ejes que rigen este dispositivo como procedimiento de resolución alternativa de conflictos. Identifica de forma clara los deberes éticos específicos de los/as mediadores/as y los deberes éticos específicos de las distintas partes y de toda otra persona que pueda intervenir en el proceso de mediación, desde una perspectiva que releva la autonomía individual de las personas, en un hacer coherente a los parámetros de autodeterminación del sujeto. A su vez, la autora enriquece este capítulo con la incorporación de los códigos de los colegios profesionales de mediadores de Europa.

El segundo capítulo se centra en la familia, comienza con los ciclos evolutivos familiares, que en el ejercicio de los roles familiares van interpelando al grupo en su totalidad, configurando problemas y conflictos propios de cada etapa de la vida familiar. El reconocimiento de los factores sociales y ambientales como elementos gravitantes en la conflictividad familiar es reconocido como parte de la mirada multidisciplinar que logra la autora para abordar la temática en estudio, que es entendido en la lógica longitudinal. Es decir, las familias afrontan cambios y dificultades en distintos momentos del proceso vital grupal y las decisiones y consecuencias de estas los acompañarán durante parte importante de sus vidas como grupo básico de la sociedad.

La consideración del dispositivo legal de la mediación familiar es recogido como un aporte del enfoque de educación para la paz que, en palabras de Acevedo, se encuentra enmarcado en una nueva cultura del divorcio, que consideraría que solo el diálogo entre las partes puede construir y resolver los problemas de manera eficaz en las distintas etapas del proceso de ruptura y reconstrucción de las relaciones entre los integrantes del grupo familiar.

En cuanto a la realidad uruguaya, presenta las principales temáticas que ingresan a atención en mediación: responsabilidad parental, tenencia (cuidado personal), régimen de visitas (relación directa y regular del niño/a con el progenitor/a con el que no vive), y pensión de alimentos. De acuerdo al Código de la Niñez y de la Adolescencia nacional, todos estos temas deben cubrirse siempre mirando el principio del interés superior del menor. Como punto central de este capítulo, la autora muestra la importancia de que el proceso de mediación familiar puede constituir una instancia de intervención que permite la protección y representación de los/as hijos/as en el trabajo cooperativo y dinámico que implica el desarrollo de nuevas formas de relaciones intrafamiliares. 
El tercer capítulo del libro considera los llamados conflictos del síndrome de alienación parental y su abordaje desde la mediación familiar, los que nutre desde el enfoque multigeneracional de Bowen, doble vinculo comunicacional de Bateson y las triangulaciones que relevó Haley, enmarcándose dentro de la teorías sistémica relacional de corte narrativo, características del equipo de Palo Alto, California.

El libro recoge las bases del síndrome de la alienación parental desde Gardner, abordando el cuestionamiento a los fundamentos teóricos de la propuesta, que se complementan con el enfoque de alienación familiar que presenta Bolaños, de la Universidad Complutense de Madrid, retomando así el enfoque relacional sistémico que atraviesa todo el libro. La autora explicita que el modelo transformativo de la mediación constituiría un enfoque valioso en la intervención en conflictos cruzados por el síndrome de alienación parental, ya que permitiría abordar el proceso de atención, desde las necesidades de las personas intervinientes en un espacio de tiempo que responda a sus intereses y que respeta el ritmo de todos sus participantes.

Dentro del proceso de trabajo que debería desarrollar la mediación en este circuito en especial, se recogen aquellas que están destinadas a la desestabilización de las cuotas fijas de poder existentes entre los sujetos en pugna, buscando con ello la construcción de roles, satisfactores y escenarios diversificados que propicien un abordaje especifico a cada situación en particular.

El texto continúa con una presentación comparada del estado de la mediación familiar y el abordaje de conflictos en esta temática, que pueden presentar problemas asociados a la tipología que describe el síndrome de alienación parental en Chile y España. Dichos países presentan modalidades muy diferentes en el ejercicio de la mediación familiar: Chile, a través de la participación del Estado, lo ordena a través de un servicio nacional licitado que entrega cobertura a todo el territorio nacional en forma gratuita; mientras que España dispone de una normativa legal, que regula el sistema de mediación desde el ámbito privado en todas las materias civiles, incluyendo lo relativo a familias. En este último país, se recoge la figura del coordinador de parentalidad, como un espacio protegido para la atención de las causas judiciales en sede de tribunal. Hacia el final del capítulo señala la importancia de continuar avanzado en la confección de normativas y políticas públicas que aborden la temática mirando siempre el interés superior del menor.

El documento finaliza en el capítulo cinco con las conclusiones, que se centran en cuatro elementos que revisados a lo largo del trabajo: 
a. La importancia de abordar la temática de los conflictos familiares con un enfoque multidisciplinar, que es propio de las disciplinas que intervienen en los temas de familia, que por la naturaleza única del sujeto de análisis que es la familia, la autora propone pueda ser abordada desde el enfoque evolutivo relacional.

b. El enfoque sistémico relacional para el abordaje de las causas de familia en lo jurídico social, que permitieron una lectura compleja de los conflictos intrafamiliares, considerando el contexto social y multigeneracional.

c. La importancia de la figura del profesional de mediación en su formación, calidad de servicio y los cuidados éticos a tener presente.

d. La responsabilidad que tiene el Estado para la instalación de procesos formativos en la gestión colaborativa y pacífica de resolución de conflictos para los/as operadores/as de justicia, en coherencia con los criterios de paz social y una sociedad menos violenta.

Respecto de la bibliografía utilizada, hay uso adecuado de los autores clásicos y emergentes de la mediación, trabaja con familias y modelos de atención en mediación familiar que permiten la construcción de conocimiento sustantivo en la temática, aplicable a Uruguay y a otros países de América Latina.

En mi opinión, el libro permite la construcción de una mirada panorámica de la mediación como mecanismo de resolución colaborativa de problemas (RAC), la complejidad de la mediación familiar como dispositivo de atención en conflictos que afectan la continuidad de las relaciones parentofiliales y, al mismo tiempo, muestra la importancia del abordaje multidisciplinar en las temáticas familiares, desde el reconocimiento de los recursos y aportes de las familias, lo que es posible mediante la atención en mediación familiar en el sistema legal vigente. 


\section{Ficha técnica}

Título: Mediación familiar y alienación parental

Autora: María José Briz Clariget

Prólogo: Carlos Alberto Gabriel Maino y María del Lujan González Tornaría

Editorial: La Ley Uruguay

Año de publicación: 2020

Ciudad y país: Montevideo, Uruguay

ISBN: 978-9974-900-59-2

Páginas: 225 